\title{
Intervención en el acto de promoción 2013 de la Facultad Regional Multidisciplinaria de Estelí (FAREM-Estelí)
}

\section{Estelí, Nicaragua 18 de Julio 2013.}

\author{
Ramona Rodríguez \\ Vice-rectora general UNAN-Managua
}

La UNAN-Managua se complace con la celebración de esta promoción de 134 nuevo profesionales que ponemos a disposición de la sociedad nicaragüense. Un sueño hecho realidad, una meta alcanzada por ustedes graduados(as), por sus familiares y, por supuesto por la universidad, nuestras felicitaciones al equipo de Decanatura, a cada uno de Ustedes Graduados(as), al Personal Docente y Personal Administrativo, por su exitosa labor, lo cual se corresponde plenamente con la misión y visión de la Facultad y particularmente con la misión y visión de la UNAN-Managua.

El Aprendizaje como actividad cognoscitiva, más el Conocimiento, conjuntamente con la construcción -apropiación de Capacidades -incluyendo las de carácter social ético-humanísticoconstituyen una síntesis unitaria histórica, objeto general de la educación superior, sentido y eje sustantivo colocado en los extremos de la organización y actividad institucional universitaria.- La relación piramidal entre esas categorías (Aprendizaje-Conocimiento-Capacidades) constituye su modo natural de existencia; y, la Ciencia, el ingrediente primordial; en consecuencia, indispensable.

Esta reflexión sobre la educación universitaria trata de prestigiar, en esta ocasión, el peso de la CIENCIA y todo lo que ello implica, tanto en el currículo (su diseño) como en la ejecución del mismo. Así que nada más oportuno que este Acto de Graduación de Profesionales de esta Facultad Regional Multidisciplinaria para celebrar la Ciencia, con su instrumento propio: la Razón, es decir, estimulando el análisis y las otras facultades que aquélla implica, a fin de cumplir las exigencias científico-cognitivas de la mejor manera posible, lo cual supone el uso de los métodos más adecuados en la conquista de metas académicas y extra-académicas.

Este contingente de 134 nuevos profesionales graduados(as) en 12 carreras son un símbolo concreto de la "fórmula" (Aprendizaje-Conocimiento-Capacidades) y, por ende, producto de la labor realizada durante la vida estudiantil de manera colegiada con los profesores, en cuyo ejercicio siempre debió estar la Ciencia, presidiéndolo todo, sin despecho -por supuesto- de la Técnica y de los Valores.

Por definición, pero sobre todo por vocación, identidad, compromiso social, dignidad profesional y práctica cotidiana, la UNAN Managua -y en este caso la Facultad Regional Multidisciplinaria de Estelí- asumen la responsabilidad correspondiente a nuestro objeto y misión, en consonancia con 
las necesidades surgidas de la realidad y con los rasgos críticos de un presente en perspectiva.

Entonces, la tesis planteada con respecto al Conocimiento, el Aprendizaje y las Capacidades, cuya esencia última y primera es la CIENCIA, adquiere una singular y suprema relevancia, al punto de convertirse en IMPERATIVO URGENTE su “re-consideración”, desde la óptica universitaria, a fin de re-valorizar su amplio contenido y posibilidades académicas, su sentido estricto y sus alcances flexibles, su vínculo con el deber social de la Universidad Pública, esto es, en cuanto a los aportes concretos más allá de la formación y profesionalización del talento humano.-

\section{¿Qué hacemos al respecto?}

Promocionar el trabajo en un ambiente, altamente participativo en la Acción, sobre la base de un Pensamiento libre, crítico y constructivo.- Someter a examen constantemente nuestro quehacer; renovar y actualizar permanentemente lo que corresponda: es el único camino que nos permite estar a la altura de los nuevos retos y al frente de las tareas, como garantía de su eficiencia y de la oportunidad de sus resultados, con lo cual afirmamos continuamente el carácter y calidad propios de una institución pública de educación superior.

Hemos tratado de poner el énfasis necesario en todos los tópicos y esferas que competen, identificando aquellos que ameritan un tratamiento priorizado. En este sentido destacamos la implementación de la nueva transformación curricular, cuya esencia es el modelo educativo centrado en la persona, un modelo que potencia el saber, el saber hacer, el saber ser y el saber estar, y está fundamentado sobre todo en los valores humanos y en la cientificidad para el abordaje de las temáticas socioculturales, económicas y políticas.

De igual manera, me permito destacar el proceso de autoevaluación institucional que se está llevando a cabo en nuestra universidad, este proceso crítico-reflexivo nos permitirá reconocer cómo la institución está desarrollando su labor, considerando la esencia de su naturaleza académica, la calidad y pertinencia del trabajo y el desempeño de la responsabilidad social; de tal manera que detectemos fortalezas y debilidades, para la toma de decisiones que conlleven al mejoramiento continuo. Por ello les invito a ustedes graduados (as) a ser parte de este proceso y a sumirlo como un espacio de análisis y reflexión del quehacer sustantivo de la Universidad, como es la docencia, la investigación científica, la extensión o proyección social y la gestión, para asegurar la mejora continua y establecer la calidad como requisito para obtener la acreditación nacional e internacional.

La UNAN Managua siempre ha puesto su mirada en la CALIDAD y la EFICIENCIA de los servicios que presta asegurando así, la IDONEIDAD y la PERTINENCIA en los resultados del producto, es decir, en el ejercicio profesional de nuestros graduados(as).- Este parámetro ha sido y será siempre un postulado irrenunciable, que informa acerca de lo que somos.

Deseo que esta reflexión acompañe el pensamiento y el ejercicio laboral-profesional de ustedes graduados(as) haciendo la debida adecuación del caso, pues la Ciencia y la calidad no es 
asunto sólo de los científicos o académicos, también es necesidad, posibilidad y requerimiento del pueblo, de todos los seres humanos; y los profesionales, son por naturaleza, los portadores inmediatos de ella, en sus contactos con las personas y grupos sociales.

No es el prestigio de la Universidad Nacional Autónoma de Nicaragua (UNAN Managua) lo que garantiza la aprobación social, la aceptación práctica y el reconocimiento nacional e internacional de nuestro quehacer y producción formativa en todos los aspectos, comenzando por el técnicocientífico, el socio-cultural y el profesional-ético-humanístico. El prestigio histórico de la UNAN Managua y de esta Facultad, en particular, más bien es un reto cotidiano para todos los universitarios, en el sentido de enaltecerlo y fortalecerlo cada vez más con nuestra labor eficiente y responsable, con nuestra dedicación, disposición y entrega.

Las iniciativas, las acciones más allá del acto docente-pedagógico, el pensamiento universitario que se produce y se reproduce en este recinto, se suceden ininterrumpidamente con libertad y diversidad; pero articulados lógicamente por una filosofía del desempeño marcada, precisamente, por una "gestión dinámica de aseguramiento cuanti-cualitativo", con los rasgos de integralidad, unidad y amplia participación.

- Graduados(as), les despido, esperando sus actividades de retro-alimentación con la Facultad. Les manifiesto todos los parabienes que se merecen, más las congratulaciones de la ocasión. Mis felicitaciones efusivas no sólo a Ustedes sino también a sus padres, cónyuges, demás parientes y amigos, por cuanto hayan contribuido a la coronación triunfal de esta carrera universitaria y por el propio regocijo que comparten.

Les despido también dejando en sus conciencias un MENSAJE CARIÑOSO y DESAFIANTE el cual bien puedo sintetizar en dos ideas:

1. Sigan el ejemplo de la Facultad conforme el Principio imperativo de CALIDAD y ÉTICA. AI igual que la Facultad, el gran prestigio de que gozamos equivale a los "laureles" sobre los que no hay que dormirse. Hay mucho qué hacer en la prestación de servicios de cada graduado(a); pero lo que no debe faltar nunca en lo que hagamos es la creatividad, la humildad, la firmeza, la perseverancia, la responsabilidad, la ética y la profesionalidad.

2. Globalicen el amor social. Busquen la cohesión social, la unidad con el pueblo como síntesis de aspiraciones y de tendencias humanas, sociales e históricas. Vayan y promuevan la solidaridad, la empatía, la cooperación, la superación social.

Ayuden a la Facultad a hacer realidad sus Principios Rectores fuera del recinto. Particularmente ejerciten, promuevan y prestigien los Principios que destacan esta promoción: "Excelencia", "Calidad" y "Profesionalismo", que les caracterizarán como una generación comprometida con el desarrollo del país, tal y como lo expresa el lema.- ESTIMADOS (AS) GRADUADOS(AS): De esta manera dejo en sus manos y conciencias una gran responsabilidad, un gran encargo que les plantea su Universidad. Nuevamente Felicidades. Buenos días a todos y todas. 